\title{
Pathogenetic heterogeneity in retinal capillary basement membrane thickening in the diabetic BB-rat
}

\author{
S. Chakrabarti and A. A.F. Sima \\ Neuropathology Research Laboratory, Department of Pathology, University of Manitoba, Winnipeg, Manitoba, Canada
}

Summary. In the present study, we compared the effects of good blood glucose control and that of aldose reductase inhibitor (Statil) treatment on diabetic retinal capillary basement membrane thickening in the diabetic BB-rat. Aggressive insulin treatment maintaining euglycaemia for 4 months prevented the characteristic basement membrane thickening in both the superficial and deep capillary beds of the diabetic retina. Statil treatment of hyperglycaemic rats for the same length of time prevented basement membrane thickening in the deep capillary bed but not in the superficial capillaries.

Key words: Retinal capillary basement membrane, BB-rat, insulin treatment, aldose reductase inhibitor.
Capillary basement membrane (BM) thickening is a characteristic structural abnormality of diabetic microangiopathy [1]. The exact mechanism(s) underlying this abnormality is (are) not known, although hyperglycaemia has been suggested to play a key role in the production of diabetic microangiopathic changes [2]. Factors thought to be involved in the thickening of BM in diabetes include non-enzymatic glycation of BM proteins and an altered synthesis of BM precursors [1, 2]. The prevention of retinal capillary BM thickening in the galactosaemic animal models by aldose reductase inhibitors (ARI) suggests that increased polyol pathway activity may play an important role in the pathogenesis of this abnormality [3, 4]. On the other hand treatment of diabetic animals with an ARI have shown conflicting results as to its preventive effect on microangiopathy $[5,6]$, suggesting that factors other than increased polyol pathway activity may account for these changes. In order to evaluate the pathogenetic role of an increased polyol pathway activity in diabetic BM thickening in retinal capillaries, diabetic BBrats treated with the ARI Statil were compared with BB-rats subjected to aggressive insulin therapy in order to achieve and maintain euglycaemia.

\section{Materials and methods}

\section{Animals}

Male prediabetic diabetes-prone BB-rats as well as non-diabetes prone male BB-rats were obtained from the University of Massachussetts, (Worchester, Mass., USA, courtesy of Dr. A.A.Like).
Three weeks after onset of diabetes, defined by detection of glycosuria and hyperglycaemia, diabetic rats were randomly assigned to various treatment groups: diabetic animals with poor diabetic control were kept insulin-deficient and maintained with small doses (0.5-3.0 U/day) of protamine zinc insulin (PZI) (Connaught Laboratories Ltd., Toronto, Ont, Canada) designed to prevent ketosis but to maintain blood glucose levels between 19.3-24.8 mmol/1 [Diabetic]. A second group of diabetic animals maintained at similar blood glucose levels received the ARI Statil, (Stuart Pharmaceuticals, ICI Americas Inc, Wilmington, Del, USA) $25 \mathrm{mg} / \mathrm{kg}$ per day [Statil(D)]. A third group of diabetic animals were treated aggressively with PZI (3.0-6.0 U/day) to achieve and maintain euglycaemia throughout the experimental period [Insulin(D)]. Age-matched non-diabetes prone BB-rats served as controls and were divided into two groups; one received no treatment [Control] and one received $25 \mathrm{mg} / \mathrm{kg}$ per day of Statil [Control(S)]. Statil was added to rat-chow $(80 \mathrm{~g}$ Statil per $100 \mathrm{~kg}$ of rat chow). All animals were maintained in individual air filtered metabolic cages as previously described [7]. Blood glucose levels were measured every second week and glycosylated haemoglobin( $\mathrm{Hb}$ ) every 3 months. Five animals in each group were killed after 4 months of treatment.

\section{Tissue collection}

The animals were anaesthetized with Na-pentobarbital $(50 \mathrm{mg} / \mathrm{kg})$ and killed by whole body perfusion with $2.5 \%$ gluteraldehyde in cacodylate buffer, $\mathrm{pH}$ 7.2. Radially oriented retinal segments from the superior temporal quadrant of the left eye within $3 \mathrm{~mm}$ of the optic nerve head were processed and examined using an electron microscope.

\section{BM thickness measurement}

Twenty cross-sectioned capillaries were measured in each animal; 10 located in the nerve fibre layer and ganglion cell layer (superficial capillary bed), and 10 in the outer plexiform layer and inner nuclear 
layer (deep capillary bed). BM thickness was measured as previously described in detail [8]. The investigator was unaware of the source of the samples.

\section{Statistical analysis}

The data are expressed as mean $\pm S E M$, and significance of differences was calculated by ANOVA, linear contrast, paired Student's ttest and linear regression by the least squares methods.

\section{Results}

Diabetic animals with or without Statil treatment showed hyperglycaemia, elevated glycosylated $\mathrm{Hb}$ levels and decreased body weights compared with control groups. Diabetic BB-rats treated aggressively with PZI showed euglycaemia, and their glycosylated $\mathrm{Hb}$ levels and body weights were similar to that of the two control groups (Table 1). The BM thickness of capillaries from the superficial capillary bed in all experimental groups was significantly greater than the corresponding BM thickness of the deep capillary bed. In the superficial capillary bed both diabetic and Statil treated animals showed a significantly $(p<0.01)$ thicker basement membrane compared to that of controls, whereas in animals treated aggressively with insulin the BM thickening was completely prevented. In the deep capillary bed diabetic animals showed significantly $(p<$ 0.002 ) thicker BM compared to the controls. However in contrast to the situation in the superficial capillary bed, the BM thickening in deep capillaries was completely prevented by both Statil treatment and aggressive insulin treatment. No significant differences were noted in any of the capillary beds between the two control groups (Table 1). BM thickening in both capillary beds was closely associated with blood glucose levels and glycosylated $\mathrm{Hb}$ values (Fig. 1).

\section{Discussion}

The present study has shown that good blood glucose control in diabetic BB-rats prevents the characteristic progressive BM tnickening in both capillary beds of the retina, suggesting that hyperglycaemia is pivotal for BM thickening in diabetic BB-rats. In contrast, treatment of hyperglycaemic animals with an ARI prevented BM thickening in the deep capillary bed but not in the superficial one, indicating that an activated polyol pathway does play a role in this process. This latter finding in hyperglycaemic BB-rats is similar to that in galactosaemic rats, in which ARI treatment prevents the BM thickening in the deep capillaries $[3,4,9]$.

The present findings, however, would suggest that biochemical events are to various degrees involved in the pathogenesis of $\mathrm{BM}$ thickening in diabetes, and may be modified by topographical and physiological differences between the two capillary beds [10]. Ambient high glucose levels appear to be the major factor in the BM thickening of the superficial arterial capillaries, probably inducing non-enzymatic glycation of structural proteins, whereas an activated polyol pathway seems to play a prominent role in the BM thickening in the venous low pressure deep capillary system. Significant associations between blood glucose levels and glycosylated $\mathrm{Hb}$ values with $\mathrm{BM}$ thickness in both capillary beds suggest that hyperglycaemia is the common initiator of BM thickening, be it due to non-enzymatic glycation of structural proteins or due to an increased polyol pathway activity via one as yet unknown mechanism.

The reason for this suggested mechanistic difference in BM thickening in the diabetic retina of BB-rats is not known. It is possible that factors like intravascular pressure differences [11] may account for a larger non-facilitated glucose permeation in a high pressure

Table 1. Intergroup comparison using ANOVA ${ }^{a} p<0.005$ and ${ }^{b} p<0.001$

\begin{tabular}{|c|c|c|c|c|c|}
\hline & \multirow[t]{2}{*}{$\begin{array}{l}\text { Blood glucose } \\
(\mathrm{mmol} / 1)\end{array}$} & \multirow[t]{2}{*}{$\begin{array}{l}\text { Body weight }{ }^{\mathrm{a}} \\
\text { (g) }\end{array}$} & \multirow[t]{2}{*}{$\begin{array}{l}\text { Glycosylated haemoglobin }{ }^{a} \\
(\%)\end{array}$} & \multicolumn{2}{|c|}{$\begin{array}{l}\text { Basement membrane thickness } \\
(\mathrm{nm})\end{array}$} \\
\hline & & & & Superficial $^{b}$ & Deep $^{b}$ \\
\hline Control $(n=5)$ & $6.4 \pm 0.9$ & $\begin{array}{r}459.8 \pm 11.8 \\
p<\end{array}$ & $1 \quad \begin{array}{l}4.3 \pm 0.6 \\
p<0.002\end{array}$ & $\underbrace{111.3 \pm 7.9}_{p<0.001}$ & $72.1 \pm\left.\right|_{p<0.002} ^{3.3}$ \\
\hline Diabetic $(n=5)$ & $17.8 \pm 3.0$ & {$[353.0 \pm 10.3-$} & $\left\lceil_{p<0.01}^{7.9 \pm 0.8-}\right.$ & $\left.\right|_{p<0.01} ^{179.6 \pm 11.9}$ & $\Gamma_{p<0.05}^{125.6 \pm 15.9}$ \\
\hline Statil (D) $(n=5)$ & $17.2 \pm 1.2$ & $\left.\right|_{p<0.001} ^{362.6 \pm 16.7}$ & $7.2 \pm 0.4$ & $\mathrm{~L}_{152.1 \pm 12.9}$ & $-93.4 \pm 7.7$ \\
\hline $\begin{array}{l}\text { Insulin (D) }(n=5) \\
\text { Control (S) }(n=5)\end{array}$ & $\begin{array}{l}5.9 \pm 1.1 \\
6.0 \pm 1.3\end{array}$ & $\begin{array}{r}-448.0 \pm 11.8 \\
473.8 \pm 25.3\end{array}$ & $\begin{array}{r}L_{5.2} \pm 0.4 \\
4.3 \pm 0.3\end{array}$ & $\begin{array}{l}124.1 \pm 10.5 \\
106.7 \pm 6.4\end{array}$ & $\begin{array}{r}-85.1 \pm 10.2 \\
68.77 \pm 8.3\end{array}$ \\
\hline
\end{tabular}

Significance of differences among various groups were judged using linear contrast. All groups showed a significantly thicker basement membrane in the superficial capillary bed compared to that of the deep capillary bed by paired Student's t-test. Data is expressed as mean \pm SEM. See text for definition of groups 


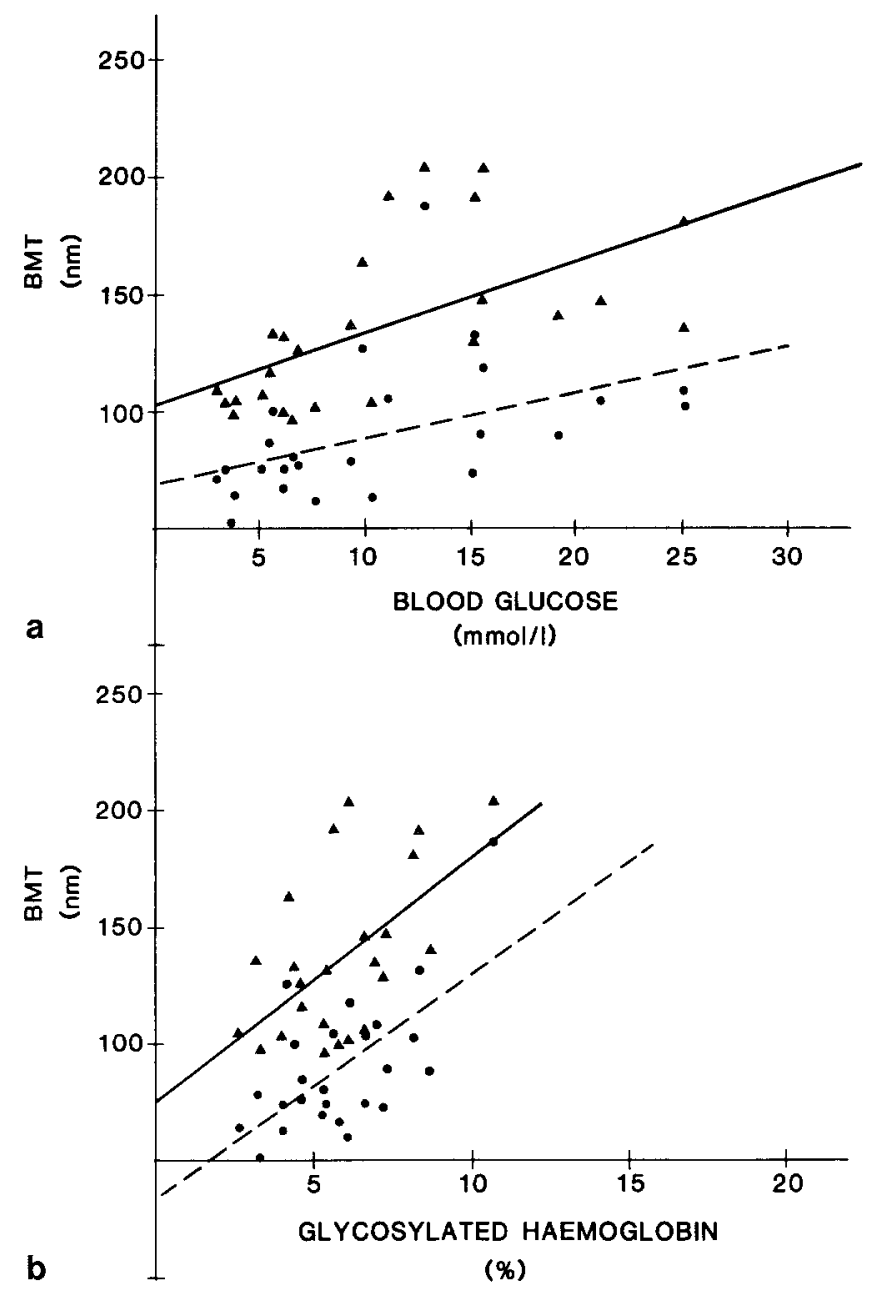

Fig. 1a and b. Regression analysis of basement membrane thickness (BMT) in retinal capillaries of the superficial $\longleftrightarrow$ and deep (---) capillary beds using a blood glucose levels as independent variable $(a=102.42, b=3.05, r=0.58, F=11.90(p<0.005)$ for the superficial capillary bed and $a=67.47, b=2.01, r=0.46, F=6.24(p<0.025)$ for the deep capillary bed], and $\mathbf{b}$ glycosylated haemoglobin values as independent variable $(a=74.73, b=10.43, r=0.58, F=11.39 \quad(p<$ 0.005 ) for the superficial capillary bed, and $a=33.80, b=9.58$, $r=0.64, F=15.55(p<0.005)$ for deep capillary bed]. The individual BMT values obtained from the superficial capillary bed are indicated by $\boldsymbol{\Lambda}$ and those from the deep capillary bed by

system allowing for a greater glucose concentration in the superficial capillary bed. This would promote nonenzymatic glycation of structural proteins, since this reaction is highly dependent on glucose concentration as well as time [12]. Other factors such as a much higher affinity of glucose to bind non-enzymatically to deoxyhaemoglobin than to oxyhaemoglobin [12] would conceptually leave less glucose available for permeation in venous capillaries. A similar reasoning may also account for the normal difference in BM thickness between the two capillary beds. However, the topographical and physiological factors responsible for this difference in therapeutic response in retinal capillaries need further evaluation.

Acknowledgements. The present study was supported by a grant from Stuart Pharmaceuticals (a divison of ICI Americas Inc.), Wilmington, Del, USA. Dr. Chakrabarti is the recipient of a post-doctoral fellowship from Juvenile Diabetes Foundation International, New York, NY, USA. We are indebted to Ms. J. McKane for preparing the manuscript.

\section{References}

1. Rohrbach DH, Martin GR (1982) Structure of basement membrane in normal and diabetic tissue. Ann NY Acad Sci 401: 203-209

2. Frank RN (1984) On the pathogenesis of diabetic retinopathy. Ophthalmology 91: 626-634

3. Frank RN, Keirn RJ, Kennedy A, Frank KW (1983) Galactose induced retinal capillary basement membrane thickening, prevention by sorbinil. Invest Ophthalmol Vis Sci 24: 1519-1524

4. Robison WG Jr., Kador PF, Kinoshita JH (1983) Retinal capillaries: basement membrane thickening by galactosemia prevented by aldose reductase inhibitor. Science 221: 1177-1179

5. Chandler ML, Shanon WA, DeSantis L (1984) Prevention of retinal capillary basement membrane thickening in diabetic rats by aldose reductase inhibitors. Invest Ophthalmol Vis Sci 25 [Suppl]: 159

6. Polsum R, Boot-Hardtford RP, Heath H (1983) The effects of long term treatment of streptozotocin diabetic rats with an aldose reductase inhibitor. Exp Eye Res 37: 507-15

7. Yagihashi S, Sima AAF (1985) Diabetic autonomic neuropathy. The distribution of structural changes in sympathetic nerves of the BB-rat. Am J Pathol 121: 138-147

8. McEwen T, Chakrabarti S, Sima AAF (1987) A rapid reproducible method for measurement of basement membrane thickness in biological structures. Comp Biol Med 17: 193-197

9. Robison WG Jr., Kador PF, Akagi Y, Kinoshita JH, Gonzalez R, Dvornik D (1986) Prevention of basement membrane thickening in retinal capillaries by a novel inhibitor of aldose reductase, Tolrestat. Diabetes 35: 295-299

10. Wise GN, Dollery CT, Henkind P (1971) The retinal circulation. Harper and Row, New York Evanstone San Francisco London, pp 21-54

11. Williamson JR, Vogler NJ, Kilo C (1971) Regional variation in width of basement membrane of muscle capillaries in man and giraffe. Am J Pathol 63: 359-370

12. Cohen MP (1986) Diabetes and protein glycosylation, measurement and biologic relevance. Springer, New York Berlin Heidelberg Tokyo, pp 5-16

Received: 20 August 1987

and in revised form: 6 October 1987

Dr. A. A. F. Sima

Neuropathology Research Laboratory

Department of Pathology

University of Manitoba

223-770 Bannatyne Avenue

Winnipeg, Manitoba, R3E OW3

Canada 